\title{
Testing of new instrument for measuring quality and diversity of nutrition in pregnancy
}

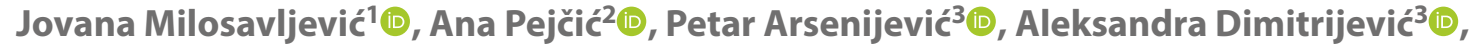

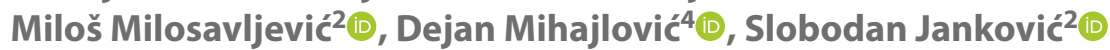 \\ ${ }^{1}$ Faculty of Medical Sciences, Department of Anatomy, University of Kragujevac, Serbia \\ ${ }^{2}$ Faculty of Medical Sciences, Department of Pharmacology and Toxicology, University of Kragujevac, Serbia \\ ${ }^{3}$ Faculty of Medical Sciences, Department of Gynecology and Obstetrics, University of Kragujevac, Serbia \\ ${ }^{4}$ Faculty of Medicine, Department of Gynecology and Obstetrics, University of Priština, Seat in Kosovska Mitrovica, Serbia
}

\begin{abstract}
Objectives: Our aim was construction and development of a new questionnaire for assessing the quality and diversity of nutrition of pregnant women.

Material and methods: This was a cross-sectional study. The novel questionnaire was developed through eight steps according with internationally accepted guidelines for questionnaire development. The questionnaire with 18 questions and answers according to the Likert's scale was created and called Balkan Food Quality and Diversity in Pregnancy Questionnaire-18 (BFQDPQ-18). Reliability testing and factor analysis of BFQDPQ-18 were carried out on a sample of 382 women in the third trimester of pregnancy whose pregnancy control and monitoring were performed at the Clinic for Gynecology and Obstetrics of the Clinical Center in Kragujevac, Serbia.

Results: The first test of reliability indicated high levels of internal consistency, with the Cronbach's alpha of 0.85 of the BFQDPQ-18. After dividing the BFQDPQ-18 into two parts of nine questions each by split-half method, the Cronbach's alphas were 0.799 and 0.716. The Kaiser-Meyer-Olkin Measure of Sampling Adequacy (KMO) was 0.878, and the Bartlett's test of sphericity: $1,892.206, \mathrm{p}<0.000$. Factor analysis revealed four factors explained in total $51.99 \%$ of the variance: mean meal and snack, foods with a low degree of industrial processing, subjective assessment of dietary quality and starchy foods.

Conclusions: The final version of the BFQDPQ-18 showed high reliability and good psychometric properties, so we believe it could be useful instrument for assessing the quality of nutrition of pregnant women.
\end{abstract}

Key words: dietary quality; dietary diversity; pregnancy; questionnaire

Ginekologia Polska 2023; 94, 1: 73-78

\section{INTRODUCTION}

Nutrition during pregnancy is very important both for normal general health and maternal nutritional status [1] and the normal development of the fetus [2]. Energy and nutrient intake in pregnancy should enable the normal function of a woman's body, the growth and development of the fetus and the timely formation of maternal energy reserves in the form of fat depots [3]. Pre-pregnancy malnutrition, as well as poor nutritional status and insufficient weight gain during pregnancy, are risk factors for preterm birth, fetal developmental disorders and difficulties in establishing lactation [4]. On the other hand, obese pregnant women and those with excessive weight gain during pregnancy are more likely to develop pregnancy-associated hypertension, gestational diabetes mellitus and delivery complications [5].

Although there are significant metabolic changes and increased nutritional and energy needs during pregnancy, the basic principles of proper nutrition that apply to the general population are also implied in pregnancy. Daily food intake should comprise products from all five food groups: fruits, vegetables, grains, protein foods and dairy [6]. Pregnant women who do not consume diverse foods are at higher risk for deficiencies in essential nutrients, which can result in fetal developmental disorders $[7,8]$. One of the most effective principles to ensure sufficient intake of nutrients during pregnancy is dietary diversification [9], which is

Corresponding author:

Miloš Milosavljević

Faculty of Medical Sciences, University of Kragujevac, Svetozara Markovića 69, 34000, Kragujevac, Serbia

Phone: +381669047886

e-mail: milosavljevicmilos91@gmail.com 
defined as the number of different food groups consumed over a specific period [10]. It is known that the use of a larger number of foods is accompanied by an increased chance of meeting the nutritional needs of the general population [11], so this could be expected in pregnant women as well.

There are several instruments used to assess the quality of nutrition of pregnant women, primarily questionnaires that basically assess the frequency of intake of certain foods in pregnancy (Food Frequency Questionnaires-FFQs) [12]. Some of the most used questionnaires of this type for assessing the quality of nutrition in pregnancy are Food Frequency Questionnaire 101 (Pregnant Women)- FFQ101 [13] and Folate Food Frequency Questionnaire-F-FFQ [14]. The advantages of these questionnaires, in addition to being freely available, are that by summarizing the data over a longer period, they can better describe a normal diet than instruments that assess the diet in a shorter time interval [12]. However, in addition to undoubtedly good psychometric characteristics and their wide use, it is important to emphasize that this type of questionnaire also has significant shortcomings. Although very detailed, these questionnaires have many questions (for example, the FFQ101 questionnaire has as many as 101 questions). It is known that with the increase in the length of the questionnaire (increase in the number of questions and increase in the number of pages), decreases the motivation of respondents to fulfill it [15]. Therefore, the aim of this study was construction and development of a new questionnaire for assessing the quality of nutrition of pregnant women, which will be based on the principles of dietary diversity, and which will be interesting and accessible to pregnant women in terms of length and number of questions.

\section{MATERIAL AND METHODS}

This was a cross-sectional study with the aim to examine the reliability and internal consistency of a new instrument for assessing the quality and diversity of nutrition in pregnant women.

\section{Construction of the novel questionnaire}

The novel questionnaire was developed through eight steps according to the guiding principle set by Robert F. DeVellis [15]. In the first part (determining the purpose of measurement), the quality and diversity of nutrition of pregnant women were chosen as the objects of measurement, due to their importance for pregnant woman's health and normal growth and development of the fetus, subjective character and impossibility of applying exact physical and chemical methods for their measurement. The second step was generation of an item pool. This was conducted after a detailed search of the literature and two separate constructive meetings of the authors. In the third step the measurement format was determined and reflected the habits in the nutrition of pregnant women according to individual groups of foods important for normal growth and development of the fetus. Five-point Likert scale with answers "completely disagree", "partially disagree", "neither agree nor disagree", "partially agree", and "completely agree", was used for answers to each question. The fourth step (revision and correction of the initial database of questions) was performed by a three-member commission of experts consisting of a specialist in gynecology and obstetrics, a specialist in hygiene and nutrition and a specialist in general medicine. As part of the fifth step, a validation question: "I always try to help other patients" was inserted into the questionnaire, with the aim of detecting the socially desirable behavior of the respondents. In the sixth step, the initial group of questions was tested on 10 pregnant women in order to examine clarity and comprehensibility of the questionnaire. Following the pilot study, a small number of changes were made and then the final Serbian version of Balkan Food Quality and Diversity in Pregnancy Questionnaire-18 (BFQDPQ-18) was copied and sent for testing of reliability on the sample of 380 female inpatients. The seventh (evaluating the questions) and eighth (optimizing the instrument size) steps were conducted through statistical processing of completed questionnaires, which is shown in more detail in the text that follows.

\section{Study population}

The study population consisted of pregnant women whose pregnancy control and monitoring were performed at the Clinic for Gynecology and Obstetrics of the Clinical Center in Kragujevac, Serbia. The Ethics Committee of Clinical Centre'Kragujevac', Serbia, approved the study, and the participants signed informed consent forms. The study included pregnant women age $\geq 18$ years in the third trimester of pregnancy (27-40 weeks of pregnancy). The exclusion criteria were age under 18 years, functional illiteracy and incomplete patient's files.

\section{Reliability testing}

Internal consistency of BFQDPQ-18 was determined by calculating Cronbach's alpha for the whole questionnaire by the Spearman-Brown "prediction" formula [16]. The second part of the reliability test was conducted through the correlation test of the scores of the two halves of the questionnaire. The questionnaire was separated into two parts by the split-half method with a similar number of items, and Cronbach's alpha was estimated for each of the parts, as well as the correlation matrices. In addition to the "split half" method, we also examined the correlation of each of the questions with the remaining part of the questionnaire without that question, as well as the correlation of all questions with each other. 


\section{Factor analysis}

Before factor analysis, we conducted the Barlett's test and the Kaiser-Meyer-Olkin (KMO) test. We used oblimin rotation with the Kaiser normalization and generalized least squares as a method of extraction. Belonging of the questions to the factors was defined by the coefficients from the "Structure matrix" and the "Pattern matrix" which reflect the correlation of the questions with the factors, i.e., the degree of participation of the factors in individual questions, respectively. The extracted factors were then properly named and explained in accordance with current theories in the field of pregnancy nutrition.

All calculations were estimated by SPSS statistical software, version 18.0 .

\section{RESULTS}

\section{Demographic characteristics of participants}

The study included 382 women in the third trimester of pregnancy. The average age of pregnant women was $29.71 \pm 5.59$ years. The oldest participant was 48 years old, while the youngest pregnant women $(n=6)$ were 18 years old. Most of the included pregnant women - 281 (73.6\%) were residents of cities and urban areas, while 101 of them (26.4\%) lived in villages and rural areas. When it comes to the level of education of pregnant women involved in the study, 20 of them (5.2\%) had primary education, 174 (45.5\%) finished secondary school, while 188 (49.2\%) had higher education levels.

The results are presented for 378 (98.95\%) participants due to incomplete data.

\section{Results of reliability testing}

We first tested the original version of the questionnaire which consisted of 22 questions. Based on the results of correlation matrix, variance, mean values, skewness and kurtosis of distribution responses for each of the question, we removed four questions. The removed questions had extreme means, also had close to zero variances and correlation coefficients as well as the greater part of other items under 0.2. In this way, we got the final version of the 18-question questionnaire. Mean values of the responses, standard deviations, skewness and kurtosis for each item are shown in Table 1.

The first test of reliability indicated high levels of internal consistency, with the Cronbach's alpha of 0.85 of the BFQDPQ-18. After dividing the BFQDPQ-18 into two parts of nine questions each by split-half method, the Cronbach's alphas were 0.799 and 0.716 . The Spearman-Brown coefficient was 0.777 and the Guttman split-half coefficient was 0.773 . Inter-item correlation before and after dividing

Table 1. Mean values, standard deviation, skewness and kurtosis of responses to items

\begin{tabular}{|c|c|c|c|c|}
\hline Item & Mean response & Standard deviation & Skewness & Kurtosis \\
\hline 1. Since I have been pregnant I have three regular meals every day & 4.33 & 1.218 & -1.827 & 2.049 \\
\hline 2. I eat a certain amount of groceries from the group of cereals every day & 3.90 & 1.226 & -1.112 & 0.235 \\
\hline $\begin{array}{l}\text { 3. I eat a certain amount of groceries from the groups of root vegetables } \\
\text { and tubers every day }\end{array}$ & 3.62 & 1.246 & -0.672 & -0.595 \\
\hline 4. I eat a certain amount of groceries from the group of legumes every day & 3.26 & 1.246 & -0.417 & -0.967 \\
\hline $\begin{array}{l}\text { 5. I eat a certain amount of groceries from the groups of meats, fish and } \\
\text { eggs every day }\end{array}$ & 4.39 & 1.065 & -1.988 & 3.174 \\
\hline $\begin{array}{l}\text { 6. I eat a certain amount of groceries from the groups of milk and milk } \\
\text { products every day }\end{array}$ & 4.55 & 0.971 & -2.606 & 6.230 \\
\hline 7. I eat a certain amount of fruits every day & 4.62 & 0.891 & -2.827 & 7.796 \\
\hline 8. I eat a certain amount of citrus fruits every day & 4.07 & 1.159 & -1.273 & 0.708 \\
\hline 9. I eat a certain amount of nuts every day & 3.49 & 1.299 & -0.588 & -0.802 \\
\hline 10. I eat a certain amount of vegetables every day & 4.50 & 0.970 & -2.379 & 5.314 \\
\hline 11. I eat a certain amount of green vegetables every day & 3.96 & 1.135 & -1.189 & 0.708 \\
\hline 12. I eat a certain amount of sugar every day & 3.55 & 1.358 & -0.585 & -0.937 \\
\hline 13. I eat a certain amount of fats or oils every day & 4.04 & 1.089 & -1.169 & 0.729 \\
\hline 14. I drink enough fluids every day & 4.63 & 0.853 & -2.837 & 8.019 \\
\hline 15. I have no problems with digesting food & 4.10 & 1.247 & -1.325 & 0.552 \\
\hline 16. I think that I eat quite well during pregnancy & 4.08 & 1.024 & -1.350 & 1.682 \\
\hline $\begin{array}{l}\text { 17. I gain weight during pregnancy exactly as much as the doctors } \\
\text { recommend }\end{array}$ & 3.86 & 1.285 & -1.063 & 0.059 \\
\hline 18. I eat so that I do not suffer from hunger & 4.25 & 1.144 & -1.653 & 1.826 \\
\hline
\end{tabular}


Table 2. Inter-item correlation before and after dividing and interclass correlation coefficient before dividing for BFQDPQ-18

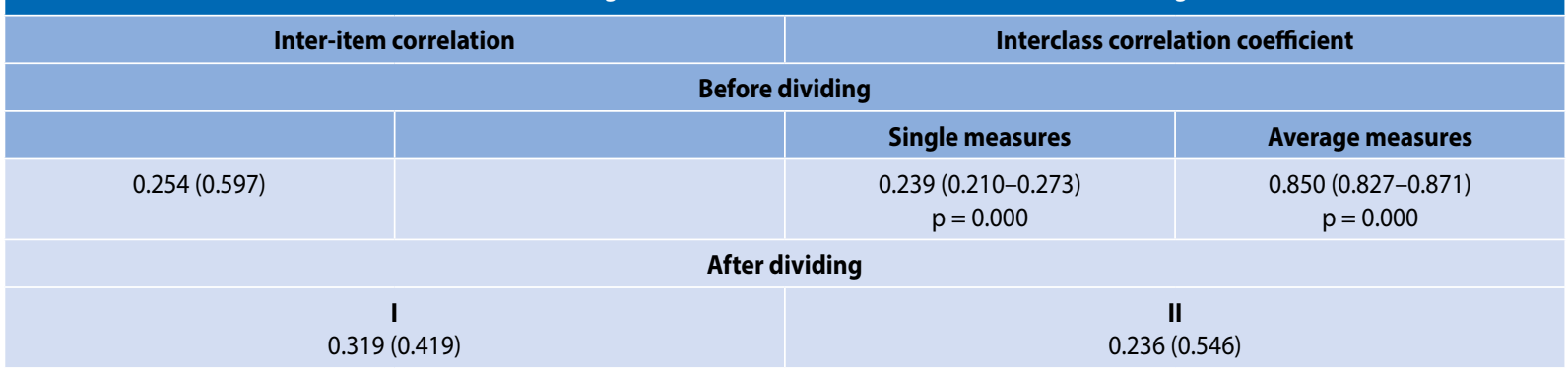

and interclass correlation coefficient before dividing for BFQDPQ-18 are shown in Table 2.

\section{Results of factor analysis}

The Kaiser-Meyer-Olkin Measure of Sampling Adequacy (KMO) was 0.878 , and the Bartlett's test of sphericity: $1,892.206, \mathrm{p}<0.000$. After oblimin rotation, we extracted four factors and explained in total $51.99 \%$ of the variance. The stop points for transfer a question to a factor was loading greater than one. The items 5, 6, 7, 8, 9, 10 and 11 belong to the first factor, which reflects mean meal and snack. The items 12 and 13 belong to the second factor and refers to foods with a low degree of industrial processing. The third factor includes items 1, 14, 15, 16, 17 and 18 and refers to subjective assessment of dietary quality. Finally, the items 2, 3 and 4 belong to the fourth factor and describe starchy foods. The rotated component matrix is shown in Table 3. The factor correlation matrix was $1-2: 0.253 ; 1-3: 0.337 ; 1-4$ : $0.282 ; 2-3: 0.267 ; 2-4: 0.060 ; 3-4: 0.240$.

Four extracted factors obtained by oblimin rotation with Kaiser normalization and generalized least squares as a method of extraction and eigenvalues for each factor and the amount of variance of the BFQDPQ-18 explained by each factor are shown in Table 4.

\section{DISCUSSION}

The final version of the BFQDPQ-18 showed high reliability and good psychometric properties, while factor analysis revealed four factors (domains, subscales): mean meal and snack (first), foods with a low degree of industrial processing (second), subjective assessment of dietary quality (third) and starchy foods (fourth). The questionnaire is easily and quickly administered (five minutes at most), while its construction followed scientific procedures which were in accordance with the recommendations for constructing questionnaires of this type. ${ }^{15}$

Four factors identified in the factor analysis refer to different, but important qualitative aspects of nutrition in pregnancy $[17,18]$ : the first factor encompasses information about eating a certain amount of groceries from the groups of meats, fish, eggs, milk, milk products, vegetables, and green vegetables (mean meal) and snacks - fruits, citrus fruits, and nuts; the second factor refers to the information about eating sugar, fats and oils, i.e., foods with a low degree of industrial processing; the third factor refers to information about how the respondent (pregnant woman) assesses her dietary quality (e.g. consumption of regular meals, adequate fluid intake, problems with digestion, opinion about eating, gaining weight in accordance with doctors recommendations, et cetera); and the fourth factor assesses information about eating starchy foods - cereals, root vegetables, tubers and legumes.

Various dietary assessment methods have been developed to estimate customary dietary intake, including the 24-hour dietary recall, diet history, FFQs, and food record during pregnancy [19]. However, each of these methods has its strengths and limitations and none of them is considered a gold standard method to measure an individual's nutritional intake $[19,20]$. In addition, methods currently used to assess nutritional status during pregnancy have limitations if one wishes to examine the overall quality of the diet [21]. Dietary assessment tools such as food records, 24-hour dietary recalls or FFQs can be used to assess diet quality, however, because they are multidimensional, a meaningful interpretation of diet quality is usually not feasible unless results are simplified into a composite score [21]. For all people, including pregnant women, it is important to evaluate all aspects of the diet rather than to limit the evaluation of nutritional status and diet quality based on one indicator, which does not explain the complexity of the diet [21]. Our questionnaire attempts to address some of these issues and provide an assessment of the overall quality and diversity of nutrition in pregnant women.

Food records and 24-hour dietary recalls may provide accurate information on diet during pregnancy, but they are expensive to administer and difficult to analyze in epidemiological studies [22]. Various FFQs have been widely used in large epidemiological studies since the 1990s [23], but after doubts of their accuracy were raised in the 2000s, numerous changes to the assessment methods have been made [23]. 


\begin{tabular}{|c|c|c|c|c|}
\hline Item & $\begin{array}{l}\text { Factor } 1 \\
\text { (Mean meal } \\
\text { and snack) }\end{array}$ & $\begin{array}{l}\text { Factor } 2 \\
\text { (Foods with a low degree } \\
\text { of industrial processing) }\end{array}$ & $\begin{array}{c}\text { Factor } 3 \\
\text { (Subjective assessment } \\
\text { of dietary quality) }\end{array}$ & $\begin{array}{c}\text { Factor } 4 \\
\text { (Starchy foods) }\end{array}$ \\
\hline $\begin{array}{l}\text { 1. Since I have been pregnant I have three } \\
\text { regular meals every day }\end{array}$ & 0.287 & 0.112 & 0.295 & 0.119 \\
\hline $\begin{array}{l}\text { 2. I eat a certain amount of groceries from the } \\
\text { group of cereals every day }\end{array}$ & 0.110 & 0.187 & 0.200 & 0.529 \\
\hline $\begin{array}{l}\text { 3. I eat a certain amount of groceries from the } \\
\text { groups of root vegetables and tubers every } \\
\text { day }\end{array}$ & -0.020 & 0.169 & 0.057 & 0.752 \\
\hline $\begin{array}{l}\text { 4. I eat a certain amount of groceries from the } \\
\text { group of legumes every day }\end{array}$ & 0.242 & -0.071 & 0.071 & 0.586 \\
\hline $\begin{array}{l}\text { 5. I eat a certain amount of groceries from the } \\
\text { groups of meats, fish and eggs every day }\end{array}$ & 0.617 & 0.148 & 0.104 & -0.056 \\
\hline $\begin{array}{l}\text { 6. I eat a certain amount of groceries from the } \\
\text { groups of milk and milk products every day }\end{array}$ & 0.509 & 0.376 & 0.136 & -0.026 \\
\hline 7. I eat a certain amount of fruits every day & 0.702 & 0.254 & 0.115 & -0.059 \\
\hline 8. I eat a certain amount of citrus fruits every day & 0.813 & -0.146 & -0.131 & 0.019 \\
\hline 9. I eat a certain amount of nuts every day & 0.617 & -0.191 & -0.092 & 0.280 \\
\hline 10. I eat a certain amount of vegetables every day & 0.340 & 0.333 & 0.209 & 0.238 \\
\hline $\begin{array}{l}\text { 11. I eat a certain amount of green vegetables } \\
\text { every day }\end{array}$ & 0.375 & 0.171 & 0.201 & 0.199 \\
\hline 12. I eat a certain amount of sugar every day & -0.047 & 0.856 & -0.131 & 0.031 \\
\hline 13. I eat a certain amount of fats or oils every day & 0.007 & 0.731 & -0.012 & 0.092 \\
\hline 14. I drink enough fluids every day & 0.314 & 0.097 & 0.554 & -0.124 \\
\hline 15. I have no problems with digesting food & 0.123 & 0.045 & 0.643 & -0.372 \\
\hline 16. I think that I eat quite well during pregnancy & 0.014 & -0.143 & 0.675 & 0.232 \\
\hline $\begin{array}{l}\text { 17. I gain weight during pregnancy exactly as } \\
\text { much as the doctors recommend }\end{array}$ & -0.015 & -1.07 & 0.457 & 0.232 \\
\hline 18. I eat so that I do not suffer from hunger & -0.178 & 0.074 & 0.700 & 0.083 \\
\hline
\end{tabular}

\begin{tabular}{|c|c|c|}
\hline Factor & Eigen value & Amount of variance explained [\%] \\
\hline Mean meal and snack & 5.547 & 30.815 \\
\hline Foods with a low degree of industrial processing & 1.419 & 7.883 \\
\hline Subjective assessment of dietary quality & 1.297 & 7.205 \\
\hline Starchy foods & 1.095 & 6.086 \\
\hline
\end{tabular}

It should be noted that FFQs refer to an advanced form of the checklist which asks respondents how often and how much food they ate over a specific period by presenting about 100 to 150 foods and take 20-30 minutes to complete [23]. They are designed to assess only dietary intake of energy and nutrients, and no other aspects of nutrition, such as food habits and eating behavior [24]. In addition, FFQs should be developed and validated specifically for each study group and research purposes because diet may be influenced by ethnicity, culture, economic status, an individual's preference, et cetera [23]. Overestimation of intake of energy and some food groups has been reported in several validation studies using FFQs compared with food records or 24-hour recalls among pregnant women [25-29], which could be explained by the fact that a large list of food items has been incorporated into them, thus providing wider selection options, while an extra source of this overestimation could be potentially inaccurate individual reporting of frequency of 
consumption and/or the amount of commonly consumed foods [19]. Also, using FFQ to measure diet in early pregnancy may be challenging considering that a significant proportion of pregnant women could experience an alteration in food preference due to nausea and vomiting during pregnancy [22].

The main limitation of this study is that it was not possible to retest the respondents after 15-30 days and to determine the temporal stability of the questionnaire. Another limitation is that the questionnaire was only tested on women in the third trimester of pregnancy. Also, the validation of our questionnaire by comparing food intake with the plasma concentrations of nutrients was not performed because it was unfeasible. Nevertheless, we demonstrated high reliability of the BFQDPQ-18, which should be additionally tested in future studies, particularly on women in the first and second trimester of pregnancy.

\section{CONCLUSIONS}

Based on the results of our study we believe that the BFQDPQ-18 is a reliable, short and useful instrument for assessing the quality of nutrition of pregnant women.

\section{Funding}

This study was partially supported by the Grant No 175007 given by Serbian Ministry of Education, Science and Technological Development.

\section{Conflict of interest}

All authors declare no conflict of interest.

\section{REFERENCES}

1. Ey CE, Zalilah MS, Ys CY, et al. et al.. Dietary diversity is associated with nutritional status of Orang Asli children in Krau Wildlife Reserve, . Malays J Nutr. 2012; 18(1): 1-13.

2. Cheng Y, Dibley MJ, Zhang X, et al. Assessment of dietary intake among pregnant women in a rural area of western China. BMC Public Health. 2009; 9: 222, doi: 10.1186/1471-2458-9-222, indexed in Pubmed: 19589154.

3. Vukovic V, Popovic J, Resimic R. Importance of proper nutrition during pregnancy. Sestrinska rec. 2016; 20(73): 7-9, doi: 10.5937/sestrec1673007v.

4. Abu-Saad K, Fraser D. Maternal nutrition and birth outcomes. Epidemiol Rev. 2010; 32: 5-25, doi: 10.1093/epirev/mxq001, indexed in Pubmed: 20237078.

5. Institute of Medicine (US) and National Research Council (US) Committee to Reexamine IOM Pregnancy Weight Guidelines; Rasmussen KM, Yaktine AL, editors. Weight Gain During Pregnancy: Reexamining the Guidelines. Washington (DC): National Academies Press (US); 2009. 5, Consequences of Gestational Weight Gain for the Mother. https://www. ncbi.nlm.nih.gov/books/NBK32818/ (01.07.2021).

6. Plećas D, Plesinac S, Kontić Vucinić O. Nutrition in pregnancy: basic principles and recommendations. Srp Arh Celok Lek. 2014; 142(1-2): 125-130, doi: 10.2298/sarh1402125p, indexed in Pubmed: 24684045.

7. Neggers $Y$, Goldenberg RL. Some thoughts on body mass index, micronutrient intakes and pregnancy outcome. J Nutr. 2003; 133(5 Suppl 2): 1737S-1740S, doi: 10.1093/jn/133.5.1737S, indexed in Pubmed: 12730492.

8. Walka H, Pollitt E. A preliminary test of a developmental model for the study of undernourished children in Indonesia. Eur J Clin Nutr. 2000;
54 Suppl 2: S21-S27, doi: 10.1038/sj.ejcn.1601002, indexed in Pubmed: 10902984.

9. Kiboi W, Kimiywe J, Chege P. Determinants of dietary diversity among pregnant women in Laikipia County, Kenya: a cross-sectional study. BMC Nutrition. 2017; 3(1), doi: 10.1186/s40795-017-0126-6.

10. Ruel MT, Ruel MT. Is dietary diversity an indicator of food security or dietary quality? A review of measurement issues and research needs. Food Nutr Bull. 2003; 24(2): 231-232, doi: 10.1177/156482650302400210, indexed in Pubmed: 12891828.

11. Ruel MT. Operationalizing dietary diversity: a review of measurement issues and research priorities. J Nutr. 2003; 133(11 Suppl 2): 3911S-3926S, doi: 10.1093/jn/133.11.3911S, indexed in Pubmed: 14672290.

12. Crozier SR, Inskip HM, Godfrey KM, et al. Dietary patterns in pregnant women: a comparison of food-frequency questionnaires and 4 d prospective diaries. Br J Nutr. 2008; 99(4): 869-875, doi: 10.1017/S0007114507831746, indexed in Pubmed: 18005481.

13. Nutritools. Tool Information: FFQ (Pregnant Women). https://www. nutritools.org/tools/140 (01.07.2021).

14. Colić Barić I, Satalić Z, Keser I, et al. Validation of the folate food frequency questionnaire with serum and erythrocyte folate and plasma homocysteine. Int J Food Sci Nutr. 2009; 60 Suppl 5: 10-18, doi: 10.1080/09637480802249074, indexed in Pubmed: 19184765.

15. DeVellis RF. Scale Development:Theory and Applications (Applied Social Research Methods), 3rd edition. SAGE Publications, Inc 2011.

16. Janković SM. Structure of design (plan) of research. In: Janković SM. ed. Research design. 1st ed. Medical Society for Rational Therapy of the Republic of Serbia (Medrat), Kragujevac 2016: 3-25.

17. Cox JT, Phelan ST. Nutrition during pregnancy. Obstet Gynecol Clin North Am. 2008; 35(3): 369-83, viii, doi: 10.1016/j.ogc.2008.04.001, indexed in Pubmed: 18760225 .

18. Koletzko B, Godfrey KM, Poston L, et al. EarlyNutrition Project Systematic Review Group. Nutrition During Pregnancy, Lactation and Early Childhood and its Implications for Maternal and Long-Term Child Health: The Early Nutrition Project Recommendations. Ann Nutr Metab. 2019; 74(2): 93-106, doi: 10.1159/000496471, indexed in Pubmed: 30673669.

19. Allehdan SS, Tayyem RF, Agraib LM, et al. Relative Validity and Reproducibility of a Food Frequency Questionnaire to Assess Food Group Intake in Pregnant Jordanian Women. J Acad Nutr Diet. 2019; 119(8): 1349-1361, doi: 10.1016/j.jand.2019.02.009, indexed in Pubmed: 31031107.

20. Lee R, Nieman D. Nutritional Assessment. 6th edition. McGraw-Hill Education, New York 2013.

21. Bodnar LM, Siega-Riz AM. A Diet Quality Index for Pregnancy detects variation in diet and differences by sociodemographic factors. Public Health Nutr. 2002; 5(6): 801-809, doi: 10.1079/PHN2002348, indexed in Pubmed: 12570888.

22. Ogawa K, Jwa SC, Kobayashi M, et al. Validation of a food frequency questionnaire for Japanese pregnant women with and without nausea and vomiting in early pregnancy. J Epidemiol. 2017; 27(5): 201-208, doi: 10.1016/j.je.2016.06.004, indexed in Pubmed: 28223084.

23. Shim JS, Oh K, Kim HC. Dietary assessment methods in epidemiologic studies. Epidemiol Health. 2014; 36: e2014009, doi: 10.4178/epih/e2014009, indexed in Pubmed: 25078382.

24. Turconi G, Celsa M, Rezzani C, et al. Reliability of a dietary questionnaire on food habits, eating behaviour and nutritional knowledge of adolescents. Eur J Clin Nutr. 2003; 57(6): 753-763, doi: 10.1038/sj.ejcn.1601607, indexed in Pubmed: 12792659.

25. Erkkola M, Karppinen M, Javanainen J, et al. Folate, vitamin D, and iron intakes are low among pregnant Finnish women. Eur J Clin Nutr. 1998; 52(10): 742-748, doi: 10.1038/sj.ejcn.1600638, indexed in Pubmed: 9805222.

26. Robinson S, Godfrey K, Osmond C, et al. Evaluation of a food frequency questionnaire used to assess nutrient intakes in pregnant women. Eur J Clin Nutr. 1996; 50(5): 302-308, indexed in Pubmed: 8735311.

27. De Vriese SR, De Henauw S, De Backer G, et al. Estimation of dietary fat intake of Belgian pregnant women. Comparison of two methods. Ann Nutr Metab. 2001; 45(6): 273-278, doi: 10.1159/000046738, indexed in Pubmed: 11786650.

28. Brantsaeter AL, Haugen M, Alexander J, et al. Validity of a new food frequency questionnaire for pregnant women in the Norwegian Mother and Child Cohort Study (MoBa). Matern Child Nutr. 2008; 4(1): 28-43, doi: 10.1111/j.1740-8709.2007.00103.x, indexed in Pubmed: 18171405.

29. Barbieri P, Crivellenti LC, Nishimura RY, et al. Validation of a food frequency questionnaire to assess food group intake by pregnant women. J Hum Nutr Diet. 2015; 28 Suppl 1: 38-44, doi: 10.1111/jhn.12224, indexed in Pubmed: 24580747. 